\title{
June 2016 Critical Care Case of the Month
}

\section{Theodore Loftsgard APRN, ACNP \\ Julia Terk $P A-C$ \\ Lauren Trapp PA-C \\ Bhargavi Gali MD}

\author{
Department of Anesthesiology \\ Mayo Clinic Minnesota \\ Rochester, MN USA
}

\section{History of Present IIIness}

A 64-year-old man underwent three vessel coronary artery bypass grafting (CABG). His intraoperative and postoperative course was remarkable other than transient atrial fibrillation postoperatively for which he was anticoagulated and incisional chest pain which was treated with ibuprofen. He was discharged on post-operative day 5 . However, he presented to an outside emergency department two days later with chest pain which had been present since discharge but had intensified.

\section{$\mathrm{PMH}, \mathrm{SH}$, and $\mathrm{FH}$}

He had the following past medical problems noted:

- Coronary artery disease

- Coronary artery aneurysm and thrombus of the left circumflex artery

- Dyslipidemia

- Hypertension

- Obstructive sleep apnea, on CPAP

- Prostate cancer, status post radical prostatectomy penile prosthesis

He had been a heavy cigarette smoker but had recently quit. Family history was noncontributory.

\section{Physical Examination}

His physical examination was unremarkable at that time other than changes consistent with his recent CABG.

Which of the following are appropriate at this time?

1. Chest x-ray

2. Electrocardiogram (ECG)

3. Troponins

4. 1 and 3

5. All of the above 


\section{Correct! \\ 5. All of the above}

His chest $x$-ray was read as unremarkable consistent with his recent CABG. ECG showed normal sinus rhythm, right bundle branch block, and diffuse ST-segment elevation. However, the ECG was unchanged from hospital discharge. Troponins were elevated at $0.20 \mathrm{ng} / \mathrm{mL}$ (normal $<0.01 \mathrm{ng} / \mathrm{mL}$ ).

He was transferred to the intensive care unit at the Mayo Clinic in Rochester. On admission his vital signs were:

- Pulse 105 beats/min

- BP 107/65 mm Hg

- Respirations 20 breaths/min

- $\mathrm{SpO} 290 \%$ on $2 \mathrm{~L} / \mathrm{min}$ by nasal cannula

His physical examination was unremarkable. However, shortly after admission his blood pressure decreased to $84 / 52 \mathrm{~mm} \mathrm{Hg}$.

Which of the following are appropriate at this time?

1. Administer crystalloids for hypotension

2. Administer tissue plasminogen activator (tPA)

3. Perform a bedside echocardiogram

4. 1 and 3

5. All of the above 


\section{Correct!}

\section{1 and 3}

The cause of his hypotension is unclear. Crytalloids can be given while investigating the cause of his hypotension. His troponins are only mildly elevated which is consistent with the cardiac injury that occurs after CABG. tPA would have a high bleeding risk given his relatively recent operation and there is no indication for its administration. Bedside echocardiography is often useful in identifying causes of hypotension in the ICU and was performed (Figure 1) (1).

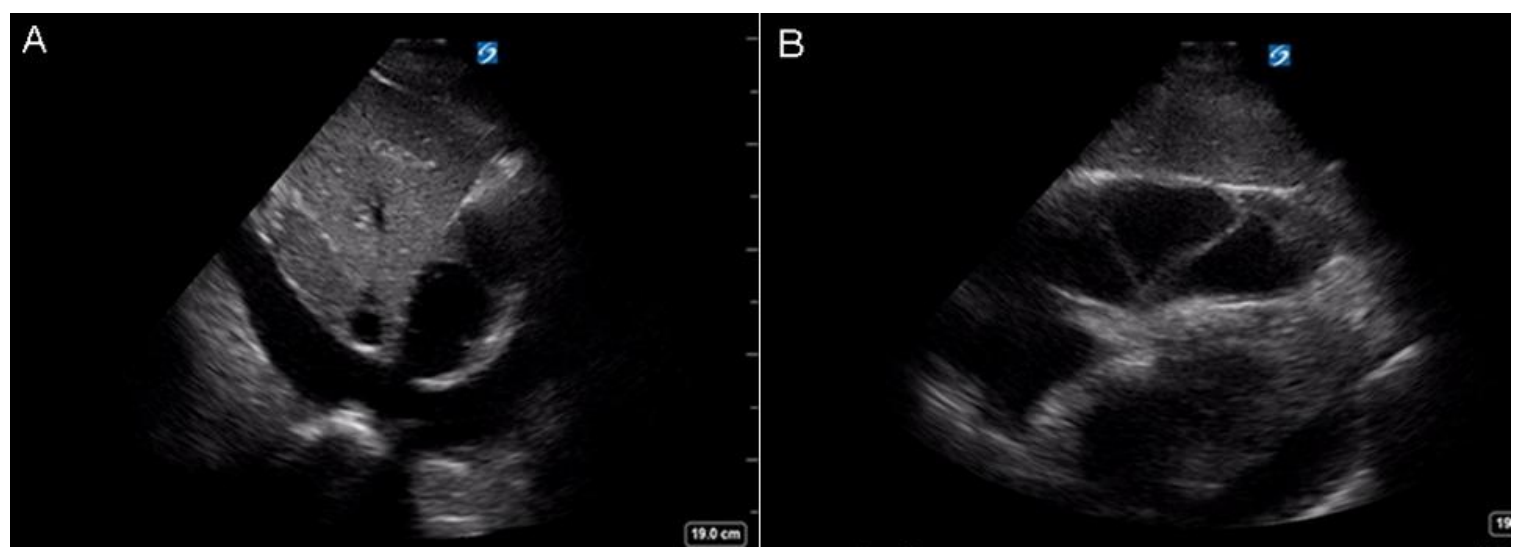

Figure 1. Two static subxiphoid views from the echocardiogram.

Which of the following is appropriate at this time?

1. Administer fresh frozen plasma

2. Discontinue the anticoagulation

3. Pericardiocentesis

4. 1 and 3

5. All of the above 


\section{Correct! \\ 5. All of the above}

The patient has a large pericardial effusion (Figure 2).

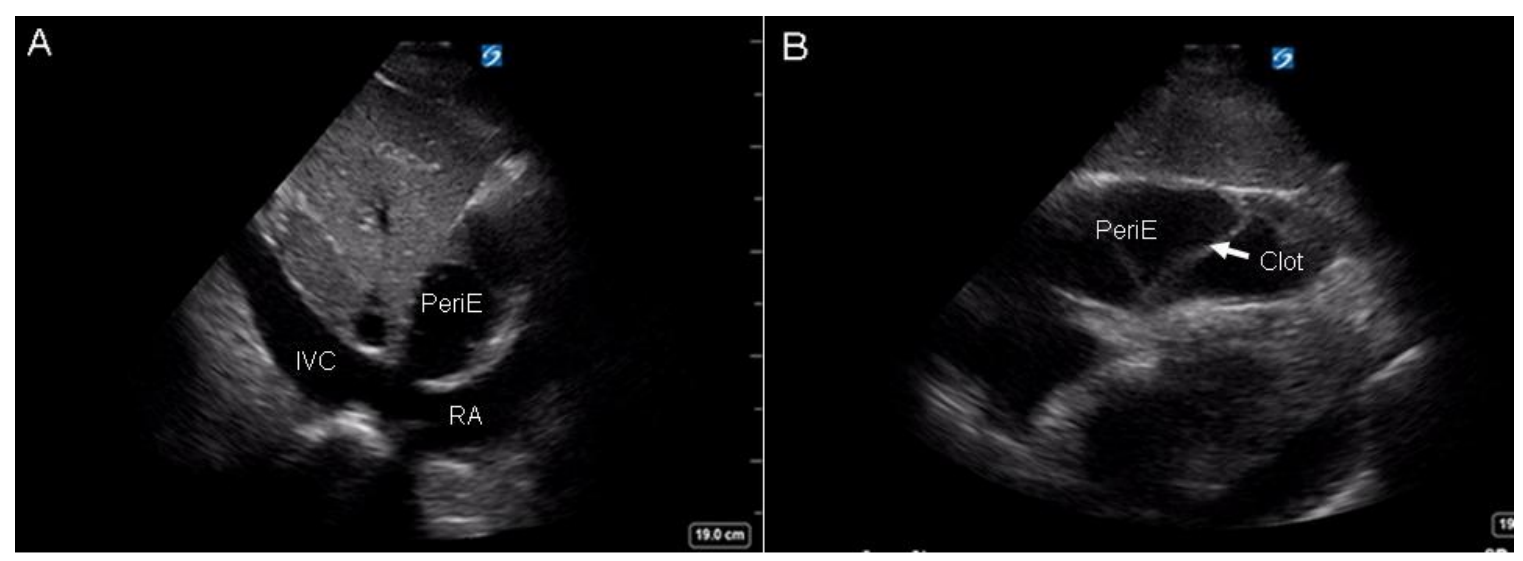

Figure 2. Panel A: Subxiphoid view from the echocardiogram with the pericardial effusion (PeriE), right atrium (RA) and inferior vena cava (IVC) labeled. Panel B:

Slightly different subxiphoid view showing the pericardial effusion and a clot which might be confused with a valve.

Furthermore, there are signs of pericardial tamponade with the right-sided chambers collapsing during diastole. After stopping the anticoagulation and administering fresh frozen plasma, pericardiocentesis was performed (2). $550 \mathrm{ml}$ of serosanguinous fluid was removed. There was immediate improvement in the blood pressure to $136 / 52 \mathrm{~mm} \mathrm{Hg}$. The patient had an eventful recovery and was discharged several days later.

\section{References}

1. Beaulieu Y. Bedside echocardiography in the assessment of the critically ill. Crit Care Med. 2007 May;35(5 Suppl):S235-49. [CrossRefl [PubMed]

2. Tsang TS, Oh JK, Seward JB. Diagnosis and management of cardiac tamponade in the era of echocardiography. Clin Cardiol. 1999 Jul;22(7):44652. [CrossRef] [PubMed] 